\title{
LA NORMATIVA ELÉCTRICA, TREINTA AÑOS DESPUÉS
}

\author{
ANTONio JiménEZ-Blanco \\ Catedrático de Derecho Administrativo \\ Universidad Politécnica de Madrid
}

\begin{abstract}
RESUMEN
El trabajo realiza un análisis del llamado «sistema eléctrico» en 1986 y en el presente 2016 para mostrar que, treinta años después, y aunque quizá con otras palabras, la regulación sigue ofreciendo casi el mismo grado de presencia de los poderes públicos y exhibiendo idénticos problemas.
\end{abstract}

Palabras clave: sistema eléctrico; regulación eléctrica; precios de la electricidad; interconexiones; bienes esenciales o de primera necesidad.

\begin{abstract}
The work is aimed at carrying out an analysis of the so called «electric system» in 1986 and in the present 2016, in order to demonstrate that, thirty years later, and perhaps with other words, the regulation continues to offer almost the same degree of presence of the public authorities and showing identical problems.
\end{abstract}

Key words: electric system; electric regulation; prices of the electricity; interconections; esential goods or goods of first need. 


\section{SUMARIO}

I. INTRODUCCIÓN.-II. BREVE REFERENCIA A LA NORMATIVA ESPAÑOLA HASTA 1986.--III. LAS NORMAS EUROPEAS HASTA 2015.--IV. NOTAS SOBRE LA EVOLUCIÓN NORMATIVA ESPAÑOLA POSTERIOR A 1986.-V. ¿LIBERALIZACIÓN?

\section{INTRODUCCIÓN}

No resultará necesario comenzar recordando que la electricidad es algo no ya singular, en el sentido de distinto de cualquier otro bien o servicio, sino incluso literalmente único. Para empezar, porque es un bien de primera necesidad y además, por contraste por ejemplo con los medicamentos, de una necesidad de las de carácter permanente: para las personas de nuestra era, y sin exagerar, casi tanto como el aire que respiramos. Y además cada vez con mayor amplitud de empleos, porque ya no es sólo, como manifestación paradigmática de la segunda revolución industrial, la luz que nos hace falta — como las antiguas velas de ceracuando el sol se pone, sino también el enchufe de los electrodomésticos, del teléfono móvil o de los ordenadores, por no citar sino los ejemplos que cualquiera tiene más a mano: la digitalización no resultaría concebible sin electricidad. Pensemos en una sucursal bancaria: no podemos ni tan siquiera imaginarnos cómo es que acaso funcionaban cuando el empleado no tenía una pantalla para consultar los saldos del cliente.

Pero a su vez con la peculiaridad (para peor) con respecto al aire de que, lejos de encontrarse naturalmente en la atmósfera a la libre $-y$ gratuita - disposición de todos sin discriminar a ricos y pobres, a hombres y mujeres, a mozos y a ancianos, la electricidad nos la tienen que haber traído. Es, en una palabra, el típico negocio de red. Y de una red, además, cuya puesta en pie no resulta precisamente barata.

Materialmente, en suma, todo un servicio público donde los haya (lo que quiera que signifique tal cosa) o, si se opta por palabras más cool y sin duda bien conocidas y contextualizadas por el amable lector, el servicio de interés económico general por antonomasia. Con una garantía de suministro para todos (domicilios, oficinas, industrias, hoteles...) expresamente proclamada en la legislación propia del sector, pero a cuyo servicio encontramos también las normas que son sabidas en el ámbito del suelo: urbanizar un terreno no significa sino transformarlo, en el sentido de civilizarlo - domesticarlo, incluso- o si se prefiere humanizarlo, y de ello forma parte no sólo el famoso acceso rodado (el automóvil es la otra criatura de la segunda revolución industrial y por cierto su 
relevancia también sigue del todo vigente), sino igualmente el suministro continuo de corriente eléctrica. Y, por supuesto, y aunque el usuario tenga que rascarse el bolsillo, porque hay que invertir mucho, todo debe tender a que el precio final resulte lo menos caro que sea posible. Un verdadero complexio oppositorum, un dilema, o como se expresan los que saben inglés, un trade-off. Por eso en ningún lugar la electricidad se produce, se distribuye y se vende conforme a las reglas de mercado en sentido literal. Los poderes públicos tienen por doquier una política energética, o, dicho con términos actuales, cuentan con su propia regulación en la materia, para intentar asegurar ese equilibrio: que la gente tenga suministro siempre (lo que significa que alguien ha tenido que comenzar por poner dinero), pero que la cosa termine resultando barata para ellos. La cuadratura del círculo, en efecto.

Detengámonos en este asunto de la economía, que, por supuesto, termina siendo, una vez más, la clave de todo.

Notorio es que las instalaciones energéticas son intensivas en capital, con la consecuencia de necesitar plazos largos - pongamos 20/30 años- para amortizarse. Y eso significa que hay que atraer a los inversores, para lo cual no basta con que los políticos de turno se abstengan de desarrollar su propensión congénita a obstaculizar lo que beneficia al procomún, sino que tienen que actuar positivamente - fomento es la palabra- y además ofrecerles (es toda una exigencia, si de verdad queremos que la garantía de suministro no se quede, como muchas veces sucede con las cosas en España, en el papel) un cierto compromiso de estabilidad. Pero bien sabemos que pedir eso a nuestros dirigentes es tanto como no conocerlos: de ellos resulta dable predicar lo de la canción de Rigoletto: La donna é mobile cual piuma al vento, muta d'accento e di pensiero. Muestras hay varias en nuestra historia reciente de que los gobiernos de todos los colores tienden, con las coartadas más varias, a mostrarse tornadizos, siempre o casi siempre, por cierto, contando con que, en caso de litigios, el Tribunal Supremo (y, últimamente, poco antes de terminar el año 2015, también, ay, el Constitucional) va a actuar de la manera genuflexa que caracteriza a la gente aplicada: la que sabe definir un ángulo perfecto de 90 grados, sin un ápice menos, a la hora de inclinar la cerviz.

El resultado de esos vaivenes es que estamos condenados a oscilar entre la insuficiencia de infraestructuras (con los consiguientes apagones, sobre todo cuando en verano nos visitan los turistas y -recordemos que, por desgracia, la electricidad no resulta almacenable_ la demanda crece: hace diez o quince años era una escena muy frecuente y que daba por cierto una imagen verdaderamente tercermundista) y, como sucede 
desde 2010, lo inverso, es decir, la sobrecapacidad instalada, con lo que ello conlleva de despilfarro a costa del consumidor (o de infrarretribución al inversor, o ambas cosas). O nos pasamos o no llegamos: o la miseria o el dispendio. Diríase que nuestro desdichado sino consiste en no terminar de dar con el punto medio de las cosas.

No hará falta consumir aquí más espacio, porque a buen entendedor pocas palabras bastan.

Pero para explicar el impacto del ordenamiento supranacional en España en los treinta años transcurridos desde el venturoso 1 de enero de 1986 hay que proceder por su orden. De entrada, recordar dónde estábamos a la sazón. Luego, exponer cuál era el listón europeo entonces y, sobre todo, cómo ha evolucionado entre tanto, porque nada hay tan dinámico, así se nos antojen de lentos los ritmos, como la integración de nuestro querido continente, que es un proceso que en efecto no puede dejar de estar siempre en marcha. Y, en fin, habrá que volver la vista al sur de los Pirineos para ver cómo nos hemos ido adaptando a esos cambios hasta llegar a hoy, en mayo de 2016.

Para que el lector de estas líneas no se quede con suspense hasta el final, se puede anticipar algo de la que va a ser la conclusión: la ordenación eléctrica española ha evolucionado, sí, en estas tres décadas - en sentido, claro es, liberalizador, al menos en teoría-, pero en mucho menor grado que lo sucedido en la mayoría de los sectores económicos. Porque Europa aquí sin duda aprieta, pero lo que se dice ahogar, no termina de hacerlo. Y también porque en materias energéticas, España se ha revelado no sólo como una isla física (que lo es, porque las interconexiones - las redes, otra vez- a través de los Pirineos continúan siendo escasísimas y sin ellas las disposiciones de Bruselas, por grandilocuentes que se antojen, valen para poco) sino igualmente como algo separado en lo que tiene que ver con lo jurídico: el que pudiésemos llamar casticismo normativo, ya abandonado (de buen o mal grado) en tantos terrenos, sigue aquí ofreciendo una resistencia verdaderamente numantina, como, de manera en extremo sintética, vamos a ver a continuación.

\section{BREVE REFERENCIA A LA NORMATIVA ESPAÑOLA HASTA 1986}

Contamos en la bibliografía española con excelentes estudios históricos - el lector los conoce bien- sobre el asunto que nos ocupa. Ahora resultará suficiente con recordar que las primeras centrales de producción de electricidad se pusieron en marcha a finales del siglo XIX utili- 
zando el agua como materia prima y teniendo como título habilitante una concesión hidráulica a perpetuidad. Las empresas (privadas y muy pequeñas) fueron ocupándose también de desplegar sus propias redes para atender a los clientes —domésticos e industriales-y en 1924, es decir, bajo Primo de Rivera, se dictó el famoso Decreto de 12 de abril, declarando formalmente servicio público el suministro de energía eléctrica, lo que de hecho significó sólo, aunque nada menos, un régimen de intervención en los precios: las tarifas.

Pero estamos, se insiste, ante algo que no se puede almacenar, de suerte que resulta indispensable una mano que en todo momento dirija al conjunto y sobre arbitre la circulación por las redes. Tiene pleno sentido que, en consecuencia, se hable del sistema eléctrico, que empezó como realidad mucho antes de que las normas consagrasen la expresión y se hablase de su explotación unificada. Es de justicia reconocer que fue una labor estrictamente privada, en el sentido de que su desarrollo (en una época además donde no había ordenadores) fue tarea de las propias sociedades, agrupadas en UNESA, y por cierto con el permanente respaldo jurídico de un entonces jovencísimo Eduardo García de Enterría. $\mathrm{Y}$ es que se trataba en todos los casos de empresas con un ámbito geográfico limitado pero que desarrollaban la actividad completa: producir, transportar y distribuir, en el bien entendido de que eso último incluía también vender. Siempre, eso sí, a las tarifas fijadas por el Gobierno de turno, con criterios, por supuesto, nada transparentes. Ya sabemos lo que era la España de entonces.

En esa línea hay que citar también la Ley 10/1966, de 18 de marzo, de Expropiación Forzosa y Sanciones en materia de instalaciones eléctricas. Se trataba de ayudar a las empresas en el despliegue de redes: una tarea que el desarrollo económico de esa época (y en singular los movimientos migratorios a las grandes ciudades) hacía indispensable.

En ese contexto del todo dirigista o, como decían los antiguos, intervencionista, aunque formalmente los actores fueran sociedades de titularidad privada, hay que mencionar la creación, en el seno del INI, de la Empresa Nacional de Electricidad, Endesa, inicialmente limitada a tareas de producción - en base a carbón-y, como es conocido, con plantas ubicadas en lugares especialmente necesitados de ayuda.

Lo anterior son sólo unas pinceladas muy breves. Pero que sirven para poner sobre la mesa la importancia de lo que pudiésemos llamar el mapa empresarial: luego ha habido, como sabemos, muchas cosas, como algunas fusiones, en primer lugar, y también la adquisición por Endesa de varias distribuidoras y simultáneamente la privatización de su capital. 
En fin, sólo queda mencionar que un poco antes del 1 de enero de 1986 (es decir, ya en plena democracia) se produjo un cambio en el régimen de propiedades, en concreto atinente a la red de transporte, que pasó a ser, como se decía entonces, nacionalizada, aunque fuera mediante el expediente indoloro de un intercambio de activos: se creó una empresa - Red Eléctrica de España, S.A.— que devino su titular. A cambio, los antiguos dueños pasaron a tener acciones de la misma. Fue la Ley 49/1984, de 26 de diciembre, (mal llamada) de explotación unificada del sistema eléctrico nacional. Mal llamada, en efecto, porque el tal sistema y también la tal explotación unificada venían siendo una realidad desde mucho antes. Pero ya se sabe que la política tiene una propensión irrefrenable por la palabrería de lujo. El art. 1 puede valer como ejemplo:

1. La explotación unificada del sistema eléctrico nacional a través de las redes de alta tensión es un servicio público de titularidad estatal. Este servicio tendrá por objeto la optimización global de dicho sistema, de acuerdo con las funciones y actividades que se desarrollan en el artículo $2^{\circ}$ de esta Ley. El servicio se gestionará mediante una Sociedad estatal, de conformidad con lo establecido en la presente Ley y las disposiciones que la desarrollen.

2. El alcance actual de la red de alta tensión es el determinado en el anexo de la presente Ley, en el que se incluyen las líneas, subestaciones, elementos de control y protección y demás instalaciones que la constituyen. El Gobierno, mediante Real Decreto, podrá modificar, si fuera preciso, el alcance de la actual red de alta tensión para el cumplimiento de las funciones y actividades reseñadas en el artículo 2, en especial en el apartado e).

La construcción de nuevas instalaciones, cuya finalidad sea la prestación del servicio, será objeto de autorizaciones administrativas, que se otorgarán del modo reglamentariamente establecido a favor de la Sociedad estatal gestora del mismo.

3. Se declara de utilidad pública, a todos los efectos legales, el servicio objeto de regulación en la presente Ley, así como los bienes y derechos afectos al mismo, teniendo la Sociedad estatal gestora a que se refiere el artículo $3^{\circ}$ el carácter de beneficiaria a efectos de expropiación forzosa.

Quiere decirse con ello que una de las fases del ciclo (la intermedia del transporte) pasó a ser desempeñada por una persona jurídica diferente. Lo que más tarde se iba a conocer como el mandato de separación de actividades.

Y otra cosa: el tal sistema eléctrico fue adoptando a lo largo de los años una segunda acepción, de naturaleza económica. Devino un patrimonio separado, cierto que sin personalidad jurídica, al que afluían, en régimen de caja única, todos los ingresos del sistema (lo obtenido 
de los consumidores en base a las tarifas) y del que luego había de salir el dinero para pagar todos los costes, todo ello mediante liquidaciones mensuales. Una especie de mutualización (palabra que se emplea aquí con todos los matices) que constituye un rasgo privativo de España y que ha sobrevivido a todo. Hoy, bien entrado el año 2016, sigue estando plenamente en pie. A ello se dirigía en especial la referencia de más arriba al casticismo, que en este terreno se ha mostrado absolutamente indoblegable. Europa nos ha consentido - ahí sí, por excepción-que sigamos siendo fieles a nosotros mismos.

\section{LAS NORMAS EUROPEAS HASTA 2015}

En lo que hace a Europa, hay que empezar poniendo sobre la mesa que, como todo el mundo sabe, y aunque la historia empezó en 1951 precisamente con la Comunidad Europea del Carbón y del Acero, lo más cierto es que en la versión inicial del Tratado de la entonces llamada CEE, de 1956, no se contuvo ninguna mención expresa a la energía, sin perjuicio, claro es, de resultar aplicables las disposiciones de alcance por así decir universal: el mercado antes llamado común y ahora interior, es decir, principio de no discriminación por razón de nacionalidad, libertades de circulación y, en fin, normas sobre derecho de la libre competencia, bien que con posibilidad de verse exceptuadas o al menos matizadas en caso de estarse ante uno de los servicios de interés económico general, noción por cierto que no se definía ni menos aún se ilustraba con el correspondiente listado. Y, además, y pese a no observarse con simpatía los monopolios, y ponerles una cláusula de stand still, con una declaración explícita en favor de la libertad de cada uno de los Estados miembros (en el origen, sólo seis) para determinar el régimen de la propiedad. Conociendo el paño, una de las típicas salvaguardias francesas.

La mejor prueba de que la energía eléctrica también resultaba alcanzada por esos principios (matizados) de libertad económica y fronteras abiertas es que una de las primeras sentencias importantes del Tribunal de Justicia, la tantas veces mencionada Costa/Enel de 15 de julio de 1964, en la que se proclamó por primera vez el sacrosanto principio de primacía, tuvo por causa precisamente una controversia en la materia que nos ocupa. En Italia se había dictado en 1962 (es decir, con posterioridad al Tratado) una norma de rango legal que, conforme al modelo francés, nacionalizaba la industria eléctrica y creaba el Ente Nazionale per l'Energia Eletrica, ENEL, dotándole de un régimen jurídico propio. En el desempeño de sus funciones, la tal ENEL emitió una factura de 
1.925 modestísimas liras contra el consumidor de Milán don Flaminio Costa, que, invocando el régimen europeo de economía de mercado y la imposibilidad de que los Estados introdujeran restricciones sobrevenidas, se negó a pagarla y fue nada menos que al Giudice conciliatore poniéndolo todo patas arriba y pidiéndole que planteara a Luxemburgo la correspondiente cuestión prejudicial, lo que en efecto hizo. El resultado (estimatorio sólo parcialmente, pero que en aquella época fue celebrado con buenas razones como un verdadero exitazo) es bien conocido porque forma parte de la mejor historia jurídica europea.

Pero ese avatar jurisprudencial no significa que Bruselas no fuese consciente de la conveniencia (al menos) de dotar a Europa de un título competencial expreso en las normas de más alto rango, lo que allí llaman una base jurídica.

Tal cosa ha terminado llegando, aunque sólo mucho después. Es, en el actual TFUE, el art. 194, con el título precisamente de Energía, y que habla de "la política energética de la Unión», es decir, algo más (y distinto) que un mero mercado interior. Y además una política que es de la Unión, no de cada uno de los Estados.

Y ello aun cuando el precepto no olvide empezar situando las cosas «en el marco del establecimiento o del funcionamiento del mercado interior». Pero siempre fijando de manera expresa los objetivos (en plural: son no ya dos, sino nada menos que cuatro) a alcanzar, siempre "con un espíritu de solidaridad entre los Estados miembros» y también (es la nueva cara de lo que va deviniendo un auténtico poliedro) «atendiendo a la necesidad de preservar y mejorar el medio ambiente». Se trata de: a) Garantizar el funcionamiento del mercado de la energía; b) Garantizar (es la misma palabra) la seguridad del abastecimiento energético en la unión; c) Fomentar (término en efecto clave) la eficiencia energética y el ahorro energético así como el desarrollo de energías nuevas y renovables; y d) Fomentar (también) la interconexión de las redes energéticas. Pero todo eso sin terminar de desapoderar a los Estados miembros, que retienen «sus posibilidades de elegir entre distintas fuentes de energía y la estructura general de su abastecimiento energético»: ya se sabe que en la dulce Francia (otra vez) lo nuclear es muy importante y despierta una oposición social menos intensa.

A ello hay que añadir lo dispuesto sobre redes transeuropeas (arts. 170 a 172) y sobre medio ambiente (arts. 191 a 193), a cuyo detalle no resulta necesario ahora descender.

Pero en el subsector de electricidad no se esperó a disponer de esa cobertura competencial explícita. Hace casi veinte años se aprobó la primera disposición en la materia: Directiva 96/92/CE del Parlamento 
Europeo y del Consejo de 19 de diciembre de 1996, con el rubro - deliberadamente modesto- de «normas comunes para el mercado interior de la electricidad». Lo mismo se llamaba la segunda Directiva (la 2003/54/CE, de 26 de junio) y la tercera (la 2009/72/CE), que es la actual. Modesto por varias razones: por hablar sólo de «mercado interior» y no de «política energética»y, además, por tratarse sólo de una Directiva, que además se limitaba a contener unas «normas comunes».

Si uno se toma la molestia de ir a su contenido, en seguida cae en la cuenta de que todo es más complicado aún, porque el autor de los textos ha sido el primero en no ignorar que aquí no se trataba sólo de integrar a unos mercados nacionales que ya fueran una realidad más o menos perfecta. Y es que tales cosas pura y simplemente no existían ni, conforme a los esquemas clásicos de la libertad económica, podían existir ni resultan concebibles para el futuro. La pretensión era otra: crear precisamente un mercado nacional en cada país (paso previo a su extensión a toda Europa), pero desde luego un mercado de la clase de los regulados, siempre según la terminología hoy al uso y — dato relevantísimo-con una autoridad pública (despolitizada, es decir, independiente de los Gobiernos: así ha de ser cada Autoridad Reguladora Nacional, ARN) a la cabeza, según establecen los arts. 36 y 37. En cuanto al contenido, y dando por supuesto que las redes (de transporte y de distribución, según una división conceptualmente discutible pero muy arraigada) constituyen monopolios naturales, se trataba de implantar e introducir el grado y la forma de competencia que, conforme a las recetas que son conocidas, resulta posible en tales casos: proclamar el régimen de libertad en la fase inicial del ciclo (la producción) y la final (la comercialización), dejando lo intermedio - las redes - en una mano inevitablemente única, aunque permitiendo el acceso a todos y en base a precios no fijados de manera unilateral, sino - subrayémoslo de nuevo- por ese árbitro que es la ARN del país (no, por favor, el Gobierno). En definitiva, introducir, de una u otra manera, lo que se tiene por el principio de separación de actividades, o sea, declarar la guerra a las empresas que se conocen con el calificativo, que pasa a ser ominoso, de «verticalmente integradas». En cierto sentido, la Ley española de 1984, más arriba referida, vino a constituir un cumplimiento anticipado (y drástico, al llegar a incidir sobre la propiedad) de dicho mandato.

Era, para emplear de nuevo unos términos que resultan muy habituales, y sin perjuicio de las eventuales obligaciones de servicio público, una típica regulación pro mercado. Pretendiendo que, en última instancia, el cliente pudiera elegir a su proveedor - de origen nacional o no-, como sucede con cualesquiera bienes o servicios. Y siendo el precio, por 
supuesto, uno de los factores determinantes de la selección por uno u otro de los que vienen a ofrecer la cosa.

Pero las normas europeas no consisten sólo en esas disposiciones favorables al mercado - en definitiva, al juego de la oferta y la demanda-, porque, a partir de 2001, y para luchar contra el cambio climático, se han dictado otras normas que van en un sentido diferente o incluso inverso: su filosofía no es mercado, mercado, mercado, sino, recogiendo la palabra que también se ha mencionado más arriba, fomento, fomento, fomento. Hoy se trata, como todo el mundo sabe, de la Directiva 2009/28/CE del Parlamento Europeo y del Consejo, de 23 de abril de 2009 , relativa al fomento del uso de energía procedente de fuentes renovables y por la que se modifican y derogan las Directivas 2001/77/CE y 2003/30/CE. El esquema resulta conocido: se fijan para 2020 unos objetivos porcentuales de producción con ese origen y, dando por cierto que no se van a poder alcanzar por sí mismos, se emplaza a los Estados (no sólo se les autoriza) a que pongan en pie «sistemas de apoyo», definidos como «cualquier instrumento, sistema o mecanismo aplicado por un Estado miembro o un grupo de Estados miembros, que promueve el uso de energía procedente de fuentes renovables gracias a la reducción del coste de esta energía, aumentando su precio de venta o el volumen de energía renovable, adquirida, mediante una obligación de utilizar energías renovables o mediante otras medidas. Ello incluye, sin limitarse a estos, las ayudas a la inversión, las exenciones o desgravaciones fiscales, las devoluciones de impuestos, los sistemas de apoyo a la obligación de utilizar energías renovables incluidos los que emplean los certificados verdes, y los sistemas de apoyo directo a los precios, incluidas las tarifas reguladas y las primas».

Tenemos en Europa, por tanto, a un regulador eléctrico bipolar: mercado por una parte (con los matices que ya conocemos) y fomento por otra. Y ello dicho además con pocos meses de diferencia: julio de 2009 y abril (o sea, un poco antes) del mismo año. Algo quizá nada infrecuente (ya sabemos lo de las dos almas: la liberal y la socialdemócrata), pero que aquí se manifiesta de una manera especialmente aguda.

Y ya en 2015, en seguida de ponerse en marcha la Comisión Juncker, se ha lanzado el ambicioso objetivo de la Unión Energética, siguiendo la huella de la recién constituida (aunque todavía incompleta) Unión Bancaria. Me refiero con ello a la llamada Estrategia Marco para la Unión de la Energía, presentada a bombo y platillo en febrero de 2015 y articulada en torno a cinco dimensiones: seguridad energética; un mercado plenamente integrado; eficiencia energética; descarbonización; y, en fin, investigación, innovación y competitividad. Por palabras que no quede. 
De hecho, cuando estas líneas se escriben, en mayo de 2016, es decir, un año largo más tarde, todo sigue más o menos igual. Entre la crisis de la deuda pública de los países del sur y la avalancha de los refugiados, Bruselas está del todo absorbida y apenas le queda tiempo, o ganas, o ambas cosas, para otros menesteres. Una pena.

\section{Notas SOBRE LA EVOLUCIÓN NORMATIVA ESPAÑOLA POSTERIOR A 1986}

Pero volvamos ahora al sur de los Pirineos y retrotraigamos el reloj a 1 de enero de 1986, cuando Europa no había dictado ninguna de esas normas específicas sobre electricidad y por tanto el legislador español se sentía menos condicionado desde fuera. Su problema era otro, el de la (débil) economía de las inversiones, que en efecto se ha terminado convirtiendo en poco menos que una enfermedad crónica. Lo peor no era que la cantidad que el público pagara no dependiera del mercado y fueran tarifas, sino la discrecionalidad gubernamental a la hora de su fijación, lo que resultaba cada vez más incompatible con la seriedad que hace falta para ir por el mundo. Por eso el Real Decreto 162/1987, de 6 de febrero, por el que se establecen tarifas eléctricas, contuvo una disposición final primera a tenor de la cual «el Ministerio de Industria y Energía elevará al Gobierno, antes de la próxima revisión general de tarifas, una propuesta de normas reguladora, de un nuevo marco que define establemente los procedimientos de cálculo de tarifas y de compensaciones entre empresas, al cual estas últimas deberán ajustar su gestión». El mandato se cumplió pronto: para dar garantías a los inversores (y a sus banqueros) de cara a los futuros ingresos - dependientes, se insiste, de la voluntad gubernamental-, y en última instancia para reducir el sobreprecio financiero que siempre se deriva del riesgo, se dictó el Real Decreto 1538/1987, de 11 de diciembre, por el que se determina la tarifa eléctrica de las empresas gestoras del servicio, el (mal llamado) «Marco legal estable». Su preámbulo es toda una confesión de sentido común y de lo que hoy llamaríamos buena regulación, entendiendo por tal la que no se empeña en algo tan peregrino como darse de bruces con la realidad e intentar diseñar un mundo ideal y platónico. A saber:

El sector eléctrico requiere, para prestar adecuadamente el servicio público que tiene encomendado, la realización de un volumen de inversiones extraordinariamente elevado, en activos fijos, que se caracterizan por un largo periodo de construcción y una vida útil muy dilatada en el tiempo. 
Su financiación exige una absorción de recursos financieros muy importante que debe ser cubierta tanto por fondos propios como por fondos ajenos y que debe ser compatible con la consecución y el mantenimiento del equilibrio económico y financiero de las empresas que componen el sector.

Proporcionar un marco de referencia estable referido al sistema de ingresos de las empresas que suministran energía eléctrica y especialmente de un componente básico de este sistema, la determinación de la tarifa eléctrica en condiciones de mínimo coste, posibilitando así la prestación del servicio en condiciones económicas adecuadas para los abonados finales, es el objeto del presente Real Decreto.

Su implantación permitirá atender a la necesidad de reducción de la incertidumbre, tanto en lo que se refiere a las decisiones públicas y privadas propias de la gestión de la actividad de suministro eléctrico como en los aspectos derivados de la consecución de una financiación adecuada de los procesos inversores que ha abordado y deberá abordar el sector.

Pero sin pasarse por el otro lado. Por lo siguiente:

Las tarifas anuales y periodificación de los ingresos anuales, de ellas derivados, deben llevar implícito un sistema de incentivos capaz de inducir a las empresas a llevar una gestión eficiente evitando sobrecostes en los procesos inversores y reunir las mejores condiciones de uniformidad en el tiempo posibles, de manera que a igual servicio corresponda igual repercusión en términos reales sobre los consumidores.

La determinación de la tarifa eléctrica debe asimismo contemplar el principio de recuperación de las inversiones en activos fijos a lo largo de su vida útil.

El sistema de determinación anual de la tarifa eléctrica tiene por objeto permitir una planificación correcta de la actividad de suministro eléctrico, supliendo las carencias del sistema anterior y dando cumplimiento al contenido de la disposición final primera del Real Decreto 162/1987, de 6 de febrero.

Así pues, se había de comenzar por calcular un coste estándar para cada una de las instalaciones existentes (incluyendo, como es natural, también las de transporte y distribución), coste que - recordemos que entonces éramos un país inflacionista - iría teniendo las correspondientes actualizaciones. Y luego habría de procederse, siguiendo lo establecido en el capítulo IV, Amortización y retribución, de la siguiente manera:

Art. 13: La amortización y la retribución que integran el coste estándar de las instalaciones complejas especializadas de generación a que se refiere el artículo $5 .^{\circ}$ de este Real Decreto se calcularán de forma que el valor estándar 
de las inversiones en ellas realizadas se recupere a lo largo de la vida útil de dichas instalaciones.

Art. 14: El período de vida útil y el procedimiento de cálculo de la amortización de los diferentes activos a efectos de la determinación de la tarifa eléctrica se establecerán por Orden del Ministro de Industria y Energía.

Art. 15: 1. La retribución resulta de la aplicación al valor actualizado neto estándar de cada activo definido en el artículo $5^{\circ}$, de una tasa de retribución anual prevista.

2. La tasa de retribución se calculará sobre la base de un tipo de interés monetario, que sea un indicador adecuado a la previsión de los precios en los mercados de capitales en los que se desenvuelve el sector y del coste de oportunidad de los fondos invertidos en el sector eléctrico.

Y eso será lo que se tenga en cuenta por el ministro del ramo cada año para la determinación de la tarifa eléctrica conforme al art. 1, a saber:

La tarifa eléctrica, como retribución global y conjunta del sistema eléctrico nacional, se fijará por aplicación del sistema de ingresos y costes estándares establecidos en el presente Real Decreto, sin perjuicio de las demás normas de aplicación.

El Ministerio de Industria y Energía, previo informe de la Junta Superior de Precios, elevará al Gobierno, para su aprobación, la propuesta de modificación de la tarifa eléctrica que corresponda por aplicación de dicho sistema, para cada ejercicio económico que comenzará el 1 de enero de cada año.

La propuesta incluirá los costes y valores estándares, la estimación de la demanda y de la desviación de los costes de los ejercicios anteriores, las tasas de actualización y retribución de los activos y demás elementos necesarios para su formulación.

En eso consistió lo dispuesto en 1987: el mensaje concerniente a quien seguía fijando anualmente los precios finales consistía en prometer que en lo sucesivo lo haría como es debido, es decir, en atención a datos (supuestamente) objetivos, y en primer lugar el valor pendiente de amortizar de cada uno de los activos.

Ya se sabe que el político celtibérico es de suyo voluble. En 1994 se aprobó, bajo la misma mayoría parlamentaria, una nueva norma general, la Ley 40/1994, de 30 de diciembre, de ordenación del Sistema Eléctrico Nacional, que iba a mantener en esencia ese esquema para lo económico. Y también por cierto en las declaraciones: el art. 2, Régimen 
de actividades, proclamó en su apartado 1 que «las actividades destinadas al suministro de energía eléctrica desarrolladas en el llamado sistema integrado (uno de los pilares, junto con el sistema independiente, del Sistema Eléctrico Nacional) constituyen un servicio público». Duró esa norma sólo tres años, aunque en su contenido hubo determinaciones llamadas a pervivir, como la formalización del mandato de separación de actividades (bien es verdad que sin llegar a exigir la diferenciación en su grado máximo, o sea, en la persona jurídica) o, dentro de la producción, la distinción entre el régimen ordinario y el especial, del cual habían de formar parte las plantas de fuentes renovables.

En 1996 cambió el signo del Gobierno. Y, con la coartada de la aprobación el mismo año de la primera de las Directivas del mercado interior de la electricidad, el legislador español — respaldado, eso sí, por la industria, que el 11 de diciembre había firmado un Protocolo con el ministro- no pudo resistir la tentación de ajustar cuentas, al menos en lo semántico, con su antecesor. La Ley 54/1997, de 27 de noviembre, del Sector Eléctrico, contiene en el preámbulo unas palabras de abjuración que, como se dice en el lenguaje taurino para aquellas faenas que los maestros despliegan cuando se sienten observados por el público, están hechas mirando al tendido del sol ( $« . .$. se abandona la noción de servicio público, tradicional en nuestro ordenamiento pese a su progresiva pérdida de transcendencia en la práctica, sustituyéndole por la expresa garantía del suministro a todos los demandantes dentro del territorio nacional»), aunque, por supuesto, el régimen de los precios para el consumidor final - lo importante - seguía siendo el de toda la vida: el art. 17 hablaba como siempre de tarifas, a fijar por el Gobierno mediante Real Decreto y anualmente. Para todo el mundo, salvo para los (pocos) consumidores cualificados. Y, por supuesto, con un art. 19 que (pese a que en el rubro de la Ley ya no se hablaba de sistema eléctrico alguno) mantenía el criterio de caja única y de liquidaciones mensuales, que es la verdadera esencia de la cosa.

Eso no significa, claro es, que la Ley de 1997 no liberalizara nada. Introdujo, a nivel mayorista, un mercado de producción (arts. 23 a 25), de manera que los que habían confiado en el Real Decreto de 1987 se vieron privados de sus garantías de recuperación de las inversiones. De ahí la famosa disposición transitoria sexta, Costes de transición a la competencia, en cuya azarosa trayectoria posterior no ha lugar a detenerse ahora.

En resumidas cuentas, una liberalización muy relativa, pero que realmente no suponía infringir los (nada exigentes, como sabemos) mandatos europeos de 1996. 
La Ley de 1997 estuvo en vigor hasta 2013, bien que con muchas modificaciones. La más importante, sin duda, la de la Ley 17/2007, de 4 de julio, dictada para adaptarse a lo dispuesto en la Directiva de 2003, pero que aprovechó para otra cosa: establecer, con efectos de 2009, la desaparición de las tarifas integrales para los consumidores. Aunque, una vez más, manteniendo el mismo régimen de fondo, sólo que ahora con el nombre de tarifas de último recurso (TUR), también — punto cruciala fijar por la autoridad política y no por ARN alguna. Y, de nuevo para parecer que se quería fortalecer la libertad de elección del consumidor final, creando nada menos que una "Oficina de Cambios de Suministrador». Parole, parole, parole.

Pero es notorio que lo sucedido entre 1997 y 2013 fue sobre todo otra cosa: y es que, como todo el mundo sabe, el régimen de contención de precios finales (pues a eso acaba conduciendo dejarle el cometido a unos políticos que siempre van a ir con la calculadora electoral a la hora de tomar decisiones) tuvo como consecuencia que los ingresos de esta industria se quedaran cada vez más cortos. Y sobre todo si se les cotejaba con unos costes que crecieron muchísimo, entre otras cosas por el exitazo en la llamada, en especial en 2007 y 2008, a los inversores de todo el mundo para que pusieran en España plantas renovables, y más que nada de tecnologías solares. La combinación de ambas cosas ha dado lugar al famoso déficit de tarifa, que es lo que explica a su vez muchas de las normas - de recorte de costes, de incremento de ingresos o de ambas cosas- dictadas a partir de 2009, con el colofón de la Ley 24/2013, de 26 de diciembre, también llamada del Sector Eléctrico, que, aunque de nuevo se presenta como dando un paso liberalizador, vuelve a mantener los precios finales intervenidos - bien que, como es obligado, con otro nombre: ahora, precio voluntario al pequeño consumidor- $-\mathrm{y}$ también respalda la subsistencia de la caja única del sistema eléctrico. Un poco antes (Real Decreto Ley 13/2012, de 30 de marzo) se había producido la adaptación a nuestro ordenamiento de la tercera (y hasta ahora última) de las Directivas, la de 2009.

Una adaptación, como se desprende de cuanto se ha explicado, incompleta, al menos en lo formal o competencial: no sucede nada malo si una autoridad pública fija precios (en ciertos aspectos, incluso debe hacerlo), pero no puede tratarse de una oficina gubernamental. De hecho, desde el 26 de febrero de 2015 (hace un año largo cuando, en mayo de 2016, estas líneas se escriben) está sobre la mesa del Gobierno español una carta de emplazamiento que, entre otros asuntos, pone el dedo acusador precisamente ahí. Y a su vez en cuatro diferentes apartados: a) Establecimiento de las tarifas de transporte y distribución; b) Ídem 
de las condiciones para la conexión y el acceso a las redes nacionales; c) Fijación de las condiciones para la prestación de servicios de balance; y d) Ídem para el acceso a las infraestructuras transfronterizas, incluidos los procedimientos para asignar capacidad y gestionar la congestión.

Hasta aquí, el reproche de Bruselas. Pero continúa faltando el siguiente paso, el Dictamen motivado.

De lo otro, los recortes de las retribuciones a los productores con fuentes renovables (se reproduce la frustrante historia del Real Decreto de 1987, aunque ahora sin el premio de consolación de los costes de transición a la competencia) hay que recordar por cierto que a la vista del silencio (cómplice) de Europa, han dado lugar a infinidad de litigios, tanto jurisdiccionales como, con invocación del Tratado de la Carta de la Energía, de arbitraje internacional. Cuando estas líneas se escriben, en mayo de 2016, ya se ha dictado alguna resolución en este último terreno, pero aún queda mucha tela que cortar. En el siglo xx hubo en España un litigio interminable, el de la Barcelona Traction. Y estos inicios del siglo XXI han reservado un lugar parecido para el ya legendario hotel Algarrobico, en la costa de Almería, y, en lo que ahora nos concierne, el régimen económico de las plantas renovables. No hay abogado que se precie que no esté teniendo ahí algún género de participación.

Y, por hache o por be, con unos precios finales - que por cierto incluyen un IVA del tipo máximo y un impuesto especial de aproximadamente el 5 por ciento - cada vez más altos. Al consumidor (sobre todo, el doméstico) todos lo quieren proteger, pero se conoce que hay cariños que matan. Y esa carestía coexiste además con el hecho de que los inversores (no sólo los productores de renovables) perciben menos de lo que debieran. Tutti discontenti. Y mucho. Qué ilusión.

\section{V. ¿LIBeralización?}

Llega la hora de concluir. El punto de partida en 1986 era el que ya sabemos: sistema eléctrico como caja única y precios finales fijados por el ministro del ramo (no por Administración independiente alguna), todo ello además en el seno de lo que sigue siendo una isla física. Hoy, en 2016, estamos - punto arriba, punto abajo- exactamente igual, palabras aparte. En teoría, el régimen jurídico de la producción y de la venta mayorista es ya muy otro, pero lo cierto es que, si acaso se ha producido incremento de la potencia instalada, que lo ha habido, lo ha sido sobre todo en plantas renovables y debido a lo favorable (hasta 2013) de su economía regulada. Y, también teóricamente, sucede que el consumidor 
tiene hoy la posibilidad de elegir a quien comprarle el producto. Pero ya se sabe que todo ello no pasan de ser meras apariencias.

Y lo peor es que Bruselas - al dictar normas o al exigir su cumplimiento- no ha hecho apenas nada por mejorar las cosas, ni Luxemburgo tampoco, porque, dejando al margen la carta de emplazamiento de 26 de febrero de 2015, que por su antigüedad, va cogiendo color amarillento, los pescozones que le ha dado a España han tenido por objeto sólo cuestiones por así decir adjetivas, como por ejemplo lo dispuesto para las operaciones corporativas de empresas que, eso sí, se dedicaban a este oficio. En los temas de fondo de la regulación eléctrica, Europa ha optado por la vieja receta de los listos en el mundo barroco: el disimulo. Pero al parecer se trataba solo de consumir páginas del $B O E$, miles y miles. Por papel que no quede. Es lo nuestro, lo español, lo castizo, aun en la era de la digitalización. Qué contento se habría puesto mi paisano Ángel Ganivet si lo hubiera visto. 
